\title{
A Parametric Study Of Window, Orientation AND SHAdING TO MINIMIZE ENERGY CONSUPTION IN MECHANICALLY Ventillated High Rise OfFice BuILdings in DHAKA, BANGLADESH
}

Asia Pac. j. energy environ.

\section{Md Shajjad Hossain}

Department of Architecture, BRAC University, Dhaka, BANGLADESH

Email for Correspondence: sshajjad@gmail.com

Manuscript Received: 01 November 2019

Revised: 11 January 2020

Accepted: 04 February 2020

Abstract

Vital statistics of a building, meaning geometric attributes, are very important design tool to manipulate energy performance of a building which is often neglected. Though a lot of recent researches focused on increasing capabilities of material and technology to build energy efficient buildings, design elements such as form, shape, window, orientation, etc. can play a very important and effective role to increase energy efficiency. The strategic design decisions about geometric attributes in the design phase costs almost nothing and can save energy bills through lifetime of the building, which is yet be specified in particular climatic region and particular building types where energy consumption matters in national scale. This paper investigates the critical proportion of façade glazing through parametric study by simulation to obtain optimum balance between luminous and thermal behavior as well as energy consumption. The context of the study is Dhaka, with tropical monsoon climate where heat and humidity is a big concern. The experiment is carried out and hence relevant to highrise office building due to its large vertical surface compared to insignificant roof area. The outcomes indicate that significant harvesting of daylight and reduction of total energy consumption by $50 \%$ comes with proper shading on large glazing on East and West facade; and $30 \%$ on South facade.

Key words

Glazing proportion, luminous environment, thermal comfort, highrise office, parametric, energy efficiency

This article is is licensed under a Creative Commons Attribution-NonCommercial 4.0 International License.

Attribution-Non Commercial (CC BY-NC) license lets others remix, tweak, and build upon work non-commercially, and although the new works must also

acknowledge \& be non-commercial.

\section{INTRODUCTION}

Geometric attributes of a building are often neglected but plays a very important role in building's energy performance. There are lot of research papers on the advancement of material and technology to aid energy efficiency of buildings. But design elements such as form, shape, window, orientation, etc. can play a very important and effective role to increase energy efficiency. The strategic design decisions about geometric attributes in the design phase costs almost nothing and can save energy bills through lifetime of the building. This paper is going to focus on few geometric attributes of buildings. For example, a fat building having a big volume would have less surface area than a slim building with same volume; and thus have the advantage of saving on energy bills in a context where cooling or heating the interior is concern. Again, in composite climate, where view and daylight is desired but heating is not, opening and glazing on north, south, east, west facade is very crucial. Proportion of window to wall also plays a significant role in energy consumption as proved in the experiment. The exercise of design and guideline is absolutely necessary for a developing country like Bangladesh where energy resource is very scarce and economy is growing.

Bangladesh is under rapid urbanization like many other developing countries in the world. Dhaka, being the capital city, is the showcase having all the concentration of development. The countries power generation is seriously low (BPDP, BSS 2012) compared to demand and despite the fact that the city is going to be flooded with high-rises to foresee future energy crisis; Because commercial buildings (Lehar, 2007) together with retail, are responsible for the 
biggest consumption and CO2 emissions (Lombard, 2008). The awareness about energy efficiency and renewable energy in high-rise commercial building is increasing along with a slow progress in field practice. Dhaka has a tropical climate where heat and humidity is a big concern. But fully air-conditioned multi-storied buildings devoid of any solar control devices, visible throughout the metropolis, are unavoidable in this era of globalization. Therefore it is important to investigate design issues and analyses separate parameters in order to increase energy efficiency.

Climate conscious design guidelines proposed by many authors which include Givoni (1992) and Königsberger (1974) for tropical context like Dhaka. Al-Homoud (1997) provided some design guidelines regarding design parameters like orientation, building form, glazing to wall ratio "Towards" optimum thermal performance in office building for cold, temperate, hot-arid and hot-humid climate, based on building energy simulation tool experiments; but he focused basically on surface to volume ratio of office buildings. Artificial lighting was only considered as internal heat source and use of natural light was not considered at all. Effect of low thermal wall insulation and insignificant impact of roof (and consequently significant impact of vertical surface) in case of high rise office building, is yet to be investigated. Bodart (2002) investigated the potential of usage of day lighting in office building and integration with artificial lighting in Belgian Climate. Though he used thermal simulation tool, found that $50 \%$ to $80 \%$ artificial lighting consumption can be saved by using day light. Danny (2001) had similar investigation with a finding of 50\% reduction in air conditioned office space in Hong kong, with indication of further improvement by reducing heat form artificial lighting and hence lowering cooling load, but it was neither measured nor investigated. In French context, Franzetti (2004) took into account both luminous and thermal behaviour of an office building when artificial and natural lighting options are coupled. She found significant relationship among day lighting, artificial lighting and heating and cooling load in temperate climate. Parys (2009) investigated on optimization of energy use for heating/cooling and lighting for a typical office room in Belgian context and climate. This study used U-value of the opaque part of the envelope, the glazing-to-wall-ratio, the shading system, the glazing type and the thermal mass as optimization variables. He found $40 \%$ glazing to wall ratio effective to achieve optimum primary energy consumption but calculated only for 1 orientation (south). Another important fact is that in this study the primary energy is consisted of heating and cooling load which has a critical relation with insulation and thermal mass. Therefore this study, though most relevant to this paper, is different because in tropical climate in Dhaka cooling is the predominant requirement, heating is not at all. Mourshed (2011) worked on cooling requirement in future climates, especially in projected increase of temperature in buildings in Dhaka but his method was based on degree days instead of full dynamic building simulation. It leaves a gap of calculating energy consumption in office buildings influenced by a many variables such as weather parameters, building characteristics, occupants and processes. Joarder (2009) and Trisha (2016) investigated day lighting performance by external and internal shading devices in high rise office building in Dhaka in one direction only, where the later author also considered thermal efficiency. Now, there is a research gap regarding glazing orientation and proportion in high rise office in Dhaka (tropical monsoon climate) to address a balance between luminous and thermal environment targeting reduced total energy consumption, which this paper aims to address.

In this investigation, a part office space (that represents single thermal zone in open plan arrangement, for simplification) is simulated that is placed in one typical floor. In terms of consumption of energy, only net energy is considered which is consumed during building operation. Detail criteria and standards for office space design in the national rules and regulations are yet to be set by the government. In the climate analysis, based on TRY (test reference year) concept and BNBC (2012) guidelines cooling energy and lighting energy calculation is most important because heating is irrelevant for number of reasons (Mallick, 1996). Therefore, total energy E(= Ec+ Ea +Eo , cooling, artificial lighting, constant ) is indicative of thermal and luminous behavior/environment (Franzetti 2004). Now minimization of the energy consumption depends on the optimization of certain responsible factors, in other words, variables. Those optimization variables are the U-value of the opaque part of the envelope, the window-to-wall-ratio, the shading system, the glazing type and the thermal mass (Parys, 2009). Examining with those factors lead to conclusion for set of choices in design stage. In this study it is assumed logical to look for the minimum net energy consumption of a typical office floor by manipulating those variables. Therefore, the target is to look for the minimum E while the Ec, Ea, Eo are variable. Simulation of appropriate models was used to compare the energy consumptions. This paper intended to find out (i) the preferable window- to- wall ratios that results in minimum net energy needs by artificial lights and HVAC systems in office buildings in Dhaka And (ii) if the ratio is changed when external (a) shading is applied in different (b) orientations.

\section{Methodology}

The optimization variables were taken from basic geometric attributes of a high-rise commercial building. Three variables were (i) orientation, (ii) the window-to-wall-ratio and (iii) shading was considered in this study. First simulation criteria and parameter were fixed. After that the model for simulation was developed. It was validated by logical reasoning after a pilot simulation. Finally with adjusted parameters and settings, simulation of all other models were done and results recorded for analysis. 


\section{Standards and Criteria}

BNBC (Bangladesh National Building Code, 1996) and Building Construction Act 2008, set criteria about building design in Bangladesh; BNBC (in the extra Gazette published in 2006) provides the criteria for air conditioned office space.

Table 1: Interior design Condition for summer_General Comfort (office)

\begin{tabular}{|c|c|c|c|c|c|c|}
\hline $\begin{array}{c}\text { Type of } \\
\text { application }\end{array}$ & $\begin{array}{c}\text { Dry Bulb } \\
\text { Temp }\left({ }^{\circ} \mathrm{C}\right)\end{array}$ & $\begin{array}{c}\text { Relative } \\
\text { Humidity } \\
(\%)\end{array}$ & $\begin{array}{c}\text { Temp. } \\
\text { Swing } \\
\left({ }^{\circ} \mathrm{C}\right)\end{array}$ & $\begin{array}{c}\text { Velocity of air } \\
\text { (between floor and } \\
1.5 \mathrm{~m} \text { level) }\end{array}$ & $\begin{array}{c}\text { Outdoor air quantity } \\
(1 / \mathrm{s} \text { per person) }\end{array}$ & $\begin{array}{c}\text { Illumination } \\
(\text { general office } \\
\text { work) }(\mathrm{lux})\end{array}$ \\
\hline BNBC & $24.5 \sim 26$ & $55-50$ & $1 \sim 2$ & Not more than $0.5 \mathrm{~m} / \mathrm{s}$ & $7.5 \sim 12.5(7.5 \mathrm{~min})$. & 300 \\
\hline
\end{tabular}

The CSA (Canadian standards association) and ASHRAE (American Society of Heating, Refrigerating, and Air Conditioning Engineers) standard recommends $24.5-28{ }^{\circ} \mathrm{C}$ at $30 \%$ relative humidity and $23-25.5{ }^{\circ} \mathrm{C}$ at $60 \%$ relative humidity. BNBC allows a temperature swing of maximum $2^{\circ} \mathrm{C}$ (for peak summer load condition). The higher range of temperature might be increased in the simulation. Mallick (1996) found that people actually might feel comfortable at nearly $30{ }^{\circ} \mathrm{C}$ provided a particular rate of air change and air flow found by in the local climate of Bangladesh. Therefore in the study here, the range is taken as $23.5-28^{\circ} \mathrm{C}$.

ICE (International commission on illumination) and ISO (International organization for standard) jointly publishes “ISO 8995-1:2002(E)/CIE S008/E: 2001 Lighting of Work Places Part 1: Indoor". It doesn't set a fixed value for lighting level for office work but suggests a close range of illumination between the work surface and vicinity, but never less than 200 lux. It also refers to standards in different countries including India (300 lux), the neighbor of Bangladesh with almost similar climatic and geographic and socio-economic characteristics in many parts. BNBC also suggest 300 lux for general office activities. Bangladesh Building Construction Act 2008 suggests the ceiling height is required (minimum) to be $2.6 \mathrm{~m}$ for air conditioned office building.

\section{Simulation Parameters}

The design variables were considered as parameters for study. All the parameters have several options depending on the contemporary practice in Dhaka. The glazing ratio usually depends on architectural design and cost analysis but for simulation following 4 options were adopted to obtain a comparable result - (1) $100 \%$ glass $+0 \%$ opaque, (2) $75 \%$ glass $+25 \%$ opaque, (3) $50 \%$ glass $+50 \%$ opaque, (4) $25 \%$ glass $+75 \%$ opaque. The windows were considered to face four main cardinal orientations (north, south, east and west). Shading for windows has many forms and designs in different buildings and accommodate change over time. Most of the buildings in Dhaka are characterized with horizontal and vertical shading devices.). A combination of vertical and horizontal shading devices with a ratio of dimensions (Rahman 2008) to ensure optimum shading on south, west and east, was adapted in simulation models.

The "parametric study" for thermal and luminous behavior of the study space was done with 3 parameters (Fig 1) as they have the major role in allowing light and heat inside. 4 orientations, 4 types of window to wall ratios and presence or absence of shading device (one type of shading device for the current study) result in 32 primary models.

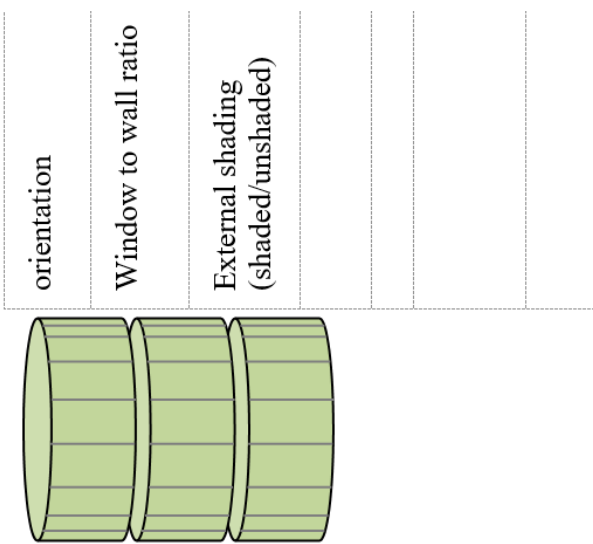

Fig1: combination of factors (like a combination lock) adiabatic

surfaces

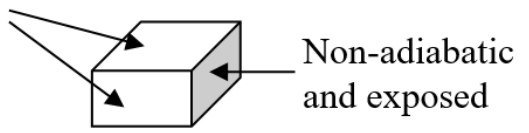

\section{Ideal Model Setting:}

Atypical office located at an intermediate floor (fig3) of a high-rise building. The orientation of the external façade is not fixed, it is a parameter. The model is not obstructed by any external object (i.e. another building). All walls, floor and ceiling are considered adiabatic except the exposed one. The room size for simulation model is $6000 \mathrm{~mm} \times 6000 \mathrm{~mm}$, (fig 4 ) 
typical high-rise column grid in Dhaka, and ceiling height is $2600 \mathrm{~mm}$ (fig2) with 3.6 persons in 36sq.m area according to Bangladesh Building Construction Act 2008. The office space is defined as one thermal zone for simulation.

It is also required to define the light measuring points inside the office space. It is logical to assume that natural light enters from the non-adiabatic surface and until what depth it would go inside depends on various factors (i.e. outdoor illumination, type and size of glazing, color of interior surface, obstruction etc.) but always the space near the opening is better lit than the farthest corner. Sometimes the artificial light is switched on to complement the daylight, it is expected to lit the farthest corner most and sometimes to lit the interior completely (i.e. at night or heavily clouded day). In either case the light measured in the middle of the room with two sensors (marked with + sign, EnergyPlus can measure (with two sensors maximum) at working surface height $(0.85 \mathrm{~m})$. The reason of placing both sensors at equal distance from window (fig 5 ) is to measure and make sure that the middle of the room achieves the minimum lighting level to meet standards.

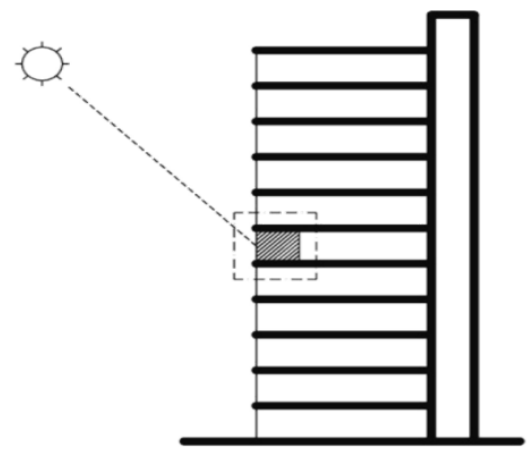

Fig 3: position of office space of a high rise building: in section

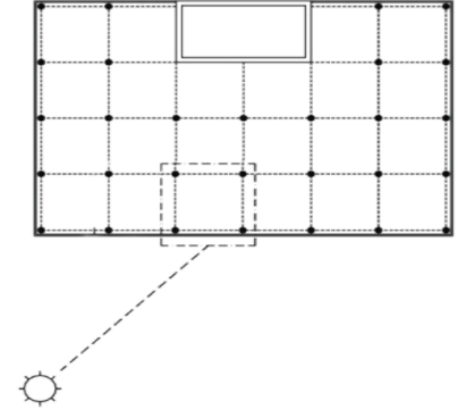

Fig 4: position of office space of a high rise building: in plan



Fig 5: position (in plan) of daylight illumination controllers $(+)$

\section{Simulation tool: energy-plus}

EnergyPlus V7.1 (developed by Department of Energy, USA) was used as energy analysis and thermal load simulation tool. Based on a user's description of a building from the perspective of the building's physical make-up and associated mechanical and other systems. EnergyPlus calculates heating and cooling loads necessary to maintain thermal control set points, using different HVAC systems. "Legacy open studio plugin 1.0.7" with Google Sketchup (fig 6) was used as input file preparing program (Preprocessor). Weather file (*.epw format) for Dhaka available from EnergyPlus website was used in simulation. The input file (*.idf) was edited with EnergyPlus's built in Text Editor (fig 7) prior to simulation.



Fig 6: Basic model built up in Sketch up open studio

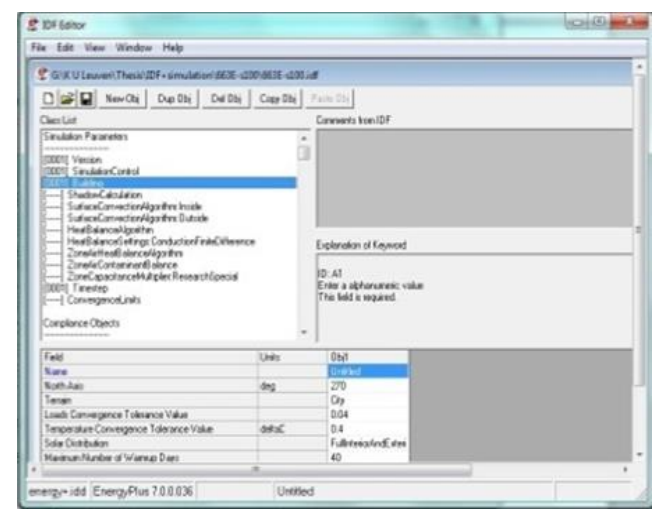

Fig 7: input file (*.idf) opened in default IDF editor

The input data file saved from the preprocessor and edited in "IDF editor" (fig 2.10) specified the building description, building energy systems, settings and output requests etc. In this study all the models had followings inputs specified: Run period, north axis, terrain character, time step/hour, site location, time zone and altitude, separate schedules for equipment, systems and human, materials and constructions, geometry rules, detailed description of each surface and fenestrations and shadings of the model, detail description of occupancy as an office space, capacity and operation of lights and other energy consuming office equipment, Daylight controllers and their sensitivity, zone infiltration rates and coefficients, HVAC template system and thermostat and at last requested output variables which include zone HVAC total electric load, total cooling energy both sensible and latent, diffuse and direct solar radiation, Zone operative and mean air temperature, daylight illumination at 2 reference points, lights electric consumption and outdoor dry bulb temperature. 


\section{Limitations}

For simplicity and time constrains, the simplest HVAC system available in EnergyPlus the "Zone: Ideal Loads Air System" was used. This system calculated cooling energy for the "thermal zone" only in terms of purchased air, exclude the energy required to move the cooled air through the HVAC system of the building. However, the intention of the study was to focus on comparison of energy consumption, not determining absolute sizing of HVAC system. Interior mean air temperature was maintained between $23.5^{\circ} \mathrm{C}$ and $28^{\circ} \mathrm{C}$ according to national regulations and that is why no schedules were provided which resulted the HVAC system to be on 24 hours. Since the zone is office space, the. Picking up and record the output (energy consumption) for the 9pm-5pm office hours (with extension of 1 or 2 hours at the beginning and end) was done.

\section{Simulation}

All the 32 models were simulated. The results from CSV files were extracted and processed through the spreadsheet (The spreadsheet with macros was prepared by Professor Dr. Frank De Troyer, KULeuven). Summation of both cooling and lighting energy was recorded to compare among the models. Following (Table 2) is a list of 4 models among 32 models prepared IDF for.

Table 2: List of 4 models for simulation

\begin{tabular}{|c|c|c|c|}
\hline Code name of model & Window Direction & Window glass percentage & Shading \\
\hline $663 S-u 25$ & South & $25 \%$ & No \\
\hline $663 S-u 50$ & South & $50 \%$ & No \\
\hline $663 S-u 75$ & South & $75 \%$ & No \\
\hline $663 S-u 100$ & South & $100 \%$ & No \\
\hline
\end{tabular}

The model 663S-u50 (fig8) was used to run simulation, removing bugs from the model and verify by the result that it was a reasonable working model; Because in the local climate of Dhaka, a window without shade on the south which has a reasonable window to wall ratio (not too big, not too small) would allow enough sunlight for a significant time of the year and significant time of the office hours to observe effects on cooling energy and daylight illumination on reference points and electric lights consumption. Although there was a heating set-point, in the output variable heating load was not requested since it was irrelevant in the context.

The walls, ceiling, floor and window comprise the single thermal zone. The window is a sub-surface of the wall. There are two daylight controllers in the middle of the room to measure the average daylight illumination throughout the space. If the daylight illumination is less than 300lux, the controllers would switch on electric lights (reversely, overhead lights dim continuously and linearly from maximum electric power-maximum light output to zero, as the daylight luminance increases).

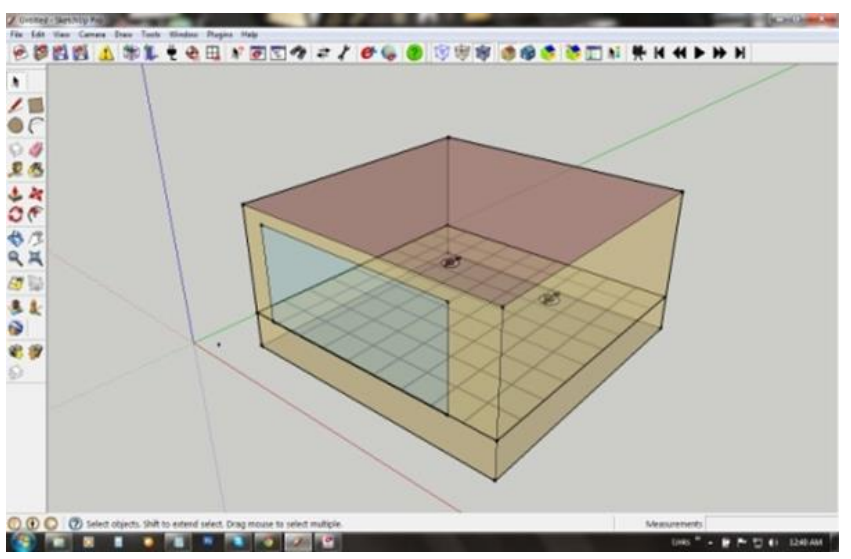

Fig 8: Geometry of Basic model 663S-u50 created in SketchUp (OpenStudio plugin)

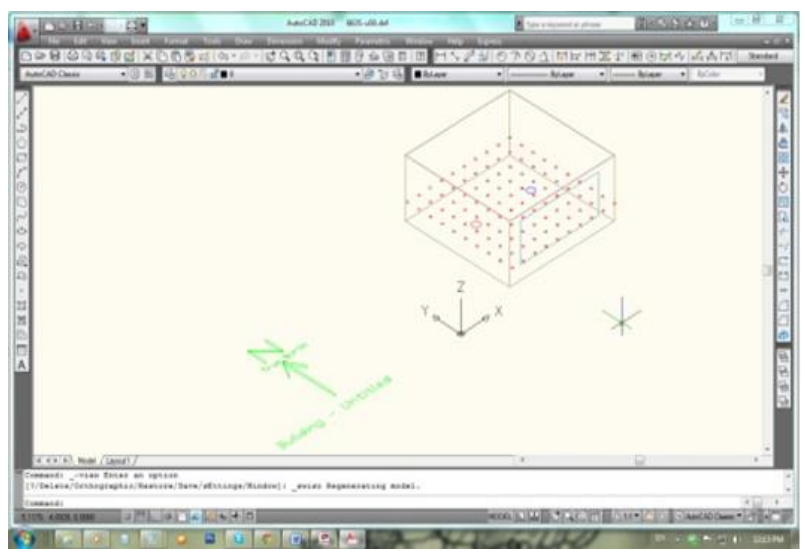

Fig9: output DXF viewed in AutoCAD

After simulation the *.dxf (fig 9) was checked for any apparent discrepancy, especially the north direction because if it is wrong there is no error reported. In the csv (comma separated value) file, there is overwhelmingly large amount of data generated for the model because it was requested for several output variables and for every hour of the whole year. For easy visualization and perception and produce usable graphical output, the data from csv file were transferred in the macro enabled spreadsheet to produce perceivable charts and graphs. The "macros" produce charts for every 10 days of the year. A snapshot of the output of the spreadsheet is given below. To produce chart every 10 days of the year make 
more than 36 charts for a year for a model. To compare and examine easily here 4 charts in 4 crucial months of the year were taken that can represent the whole year. Those days would be middle 10 days of March (12th -21st), June (10th 19th), September (8th -17st) and December (7th -16st); having Solstice and equinox in mind.

\section{JUSTIFICATION}

2 output charts, from the simulation of model 663S-u50, are discussed for explanation and justification. The variables are scaled in the chart for better perception.

The chart of March (12th -21st) (Fig 12): 3 kinds of temperatures were requested in output such as outdoor dry bulb (DBT), indoor mean air temperature (MAT) and zone operative temperature (ZOT). The diurnal variation of DBT is maximum among these 3 kinds of temperatures, as expected. Since it's a model without natural ventilation, the indoor temperature MAT is supposed to get higher in daytime and lower in nighttime following the DBT but with a time shift that represent thermal lag, and operative temperature ZOT is supposed to lay in between. The chart shows the expected character. MAT shows a linear character at $28^{\circ} \mathrm{C}$, which is the higher thermostat set point, at office hours; but the outdoor DBT and ZOT is higher (highest at 2 3pm) during day and cooling energy follows the same trend. It proves the HVAC system is working to keep the interior cool. Since the HVAC system is on 24 hours, MAT continues the linear trend after office hours (see yellow marking in the chart) and drops after midnight (the vertical lines in the chart with numbers shows hour counts and the yellow highlighted part indicate 9-5 office hours) when the system already has removed enough heat to drop the temperature below $28^{\circ} \mathrm{C}$ and the cooling energy is 0 at that hours. It resumes going up again slightly before the office hour starts. Difference between the highest and lowest points of ZOT is much lower than DBT which indicate the thermal mass of the wall (which is $200 \mathrm{~mm}$ concrete block and $10 \mathrm{~mm}$ cement plaster- exposed to outdoor). This is the logical thermal behavior of the enclosed model during March, a hot summer month.

The electric consumption is at minimum level and consistent during day time and shows a jump in the end of office hour in most days. This is because the controllers switch on the lights towards higher capacity as required to maintain the asked lux-level. From the luminous behavior of the model, it seems that the last hours (and first 1 hour for some models in winter months) of office are crucial to take the electric consumption of lights into account.

The chart of June (10th -19th) (Fig 13): It is little different from March. The diurnal temperature variation is much lower which might be explained by low (extremely low for 50\% days) direct radiation and high indirect radiation which means high cloud cover. The fact is also supported by the data provided in the climate chapter: lowest sunshine hours in June and second highest rainfall $(350 \mathrm{~mm})$ month of the year. Despite being diurnal temperature variation, the minimum temperature is not very low, it is always more than $25{ }^{\circ} \mathrm{C}$ (it was less than $20{ }^{\circ} \mathrm{C}$ at night in March) - cause 2 behavioral changes in MAT and cooling energy. The amplitude of the curve for cooling energy is much lower, almost half compared to that of March(see yellow marking in the chart) but the lowest point is barely touching the 0 line, which means cooling is required for all most all the hours virtually. However, to take into account the office hours, the total cooling load is much lower. For example, one typical day in March, the cooling energy was 44MJ and in June 37MJ (for 9am-5pm).

The change in luminous behavior is more subtle. The maximum time of office hours, the daylight illumination at both reference points is 1000 1500 lux (2000 3500 lux in March). Since its not less than 300lux (it is to be remembered that it's normal for a south window without shading) the artificial lights consumption is at zero or at a minimum level (according to type of daylight controller) and the jump in the last hour of office is much lower which is $4 \sim 5 \mathrm{MJ}$ (7 8 MJ in March). Most interestingly the curve for daylight illumination at ref. point 1 and 2 is almost identical in June, despite their equal distance from window but to the east-west relative to each other, (fig. 10, 11) whereas it showed a shift of peak with time in March, which again support the phenomena of low direct radiation and high indirect radiation, high cloud cover and high rainfall. It should be mentioned here that daylight illumination at a point inside the office space might vary depending on the type of glazing, blinds and louvers etc. Therefore, the daylight illumination reported here is due to one given condition.

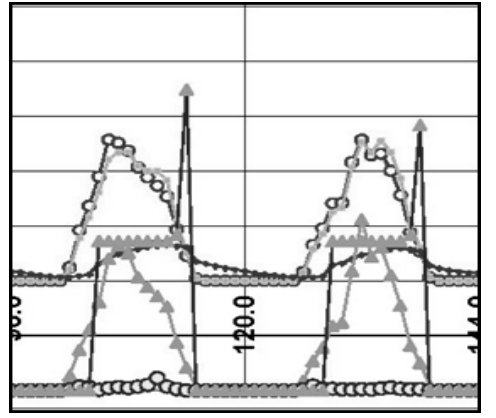

Fig10: Daylight illumination in June



Fig 11: Daylight illumination in March 


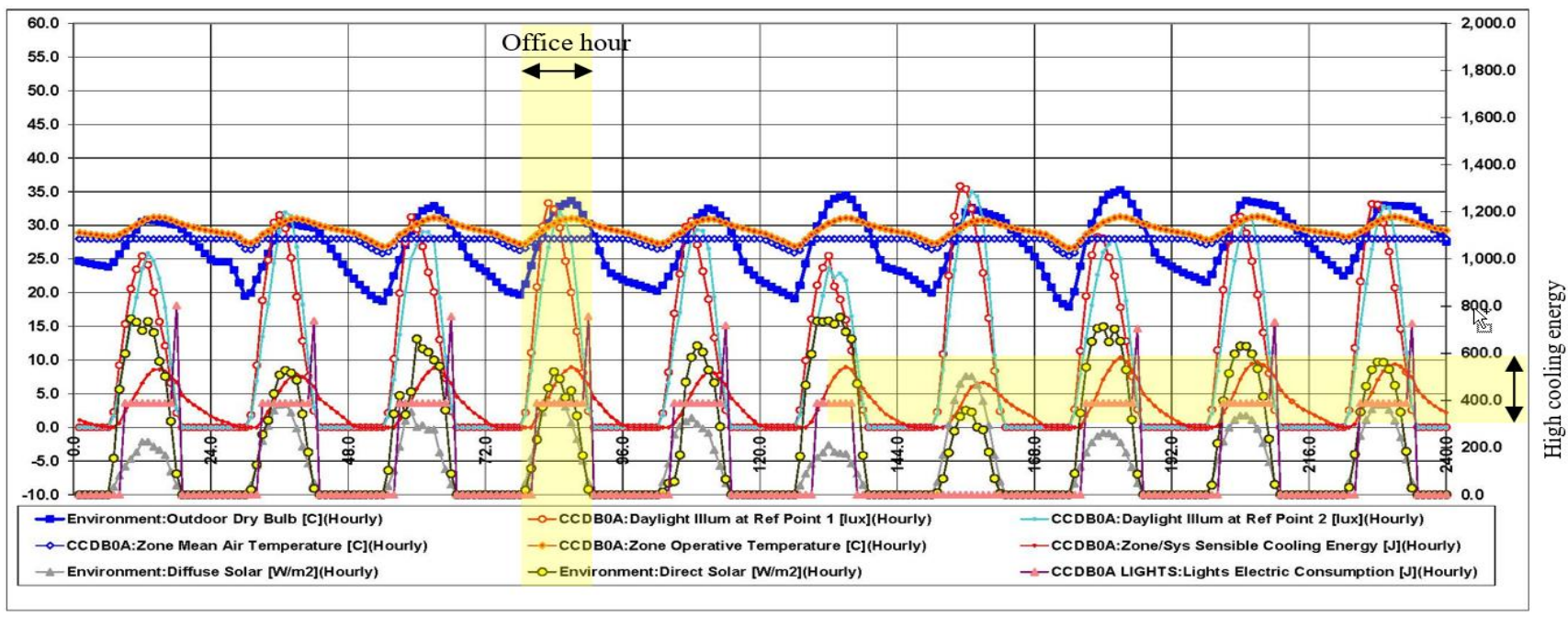

Fig 12: output variable for 663S-u50/March $\left(12^{\text {th }}-21^{\text {st }}\right)$

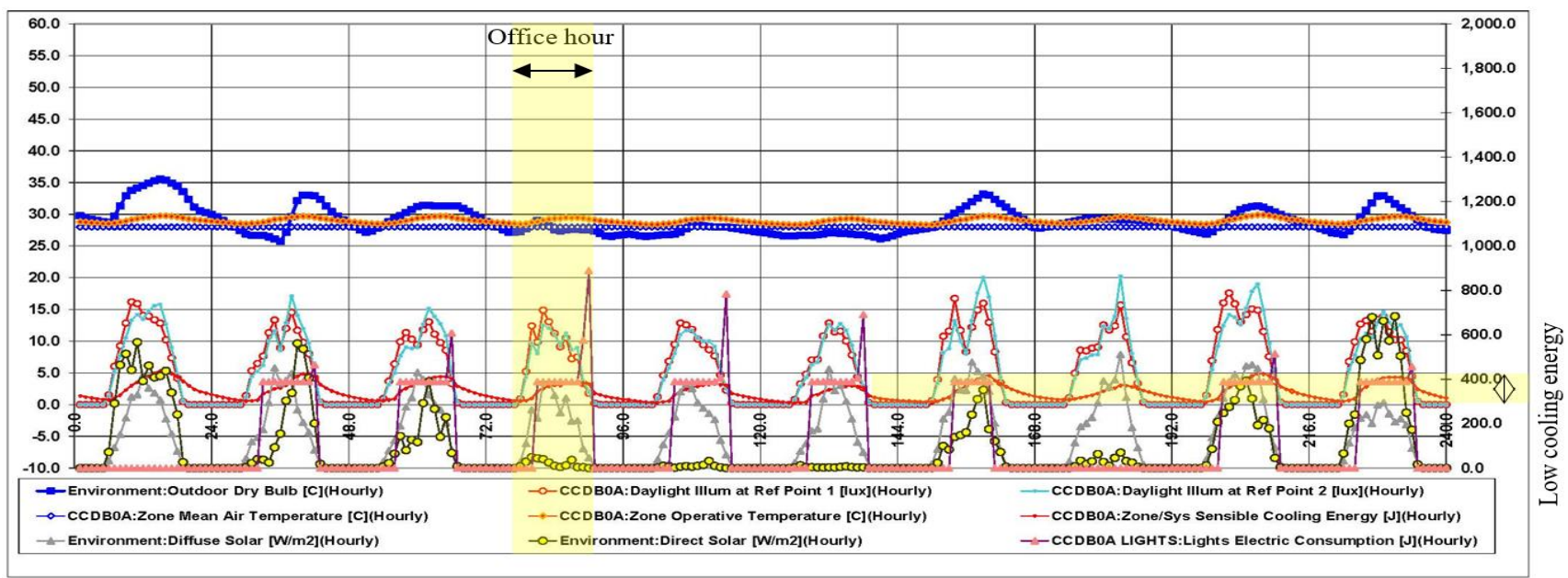

Fig 13: output variable for 663S-u50/June (10th - 19th)

\section{ANALYSIS AND SyNTHESIS OF RESULTS}

The charts show part of the year- each showing 10 successive days of a month. They can portray a partial picture of the model's energy requirements. Therefore to compare among all the models, the total cooling and lighting energy (table 3 ) for the whole year for all models were calculated.

Table 3: Effect of window to wall ratio on reduction of total energy

\begin{tabular}{|c|c|c|c|c|c|c|c|c|}
\hline model & $\begin{array}{c}\text { Total energy } \\
(\mathrm{GJ})\end{array}$ & $\begin{array}{c}\text { Increase } \\
(\%)\end{array}$ & model & \begin{tabular}{|c}
$\begin{array}{c}\text { Total energy } \\
(\mathrm{GJ})\end{array}$ \\
\end{tabular} & $\begin{array}{c}\text { Increase } \\
(\%)\end{array}$ & model & $\begin{array}{c}\text { Total energy } \\
(\mathrm{GJ})\end{array}$ & $\begin{array}{c}\text { Increase } \\
(\%)\end{array}$ \\
\hline $663 N-u 100$ & 23.05 & \multirow{4}{*}{$46 \uparrow$} & 663S-u100 & 42.33 & \multirow{4}{*}{$70 \uparrow$} & 663E-u100 & 37.73 & \multirow{4}{*}{$60 \uparrow$} \\
\hline $663 \mathrm{~N}-\mathrm{u} 75$ & 20.55 & & 663S-u75 & 36.51 & & 663E-u75 & 32.89 & \\
\hline $663 \mathrm{~N}-\mathrm{u} 50$ & 17.30 & & $663 S-u 50$ & 28.88 & & 663E-u50 & 26.62 & \\
\hline $663 \mathrm{~N}-\mathrm{u} 25$ & 15.75 & & 663S-u25 & 24.85 & & 663E-u25 & 23.57 & \\
\hline $663 W-u 100$ & 37.79 & \multirow{4}{*}{$64 \uparrow$} & $663 \mathrm{~N}-\mathrm{s} 100$ & 19.64 & \multirow{4}{*}{$27 \uparrow$} & 663S-s100 & 28.43 & \multirow{4}{*}{$63 \uparrow$} \\
\hline 663W-u75 & 32.85 & & $663 N-s 75$ & 17.42 & & 663S-s75 & 24.61 & \\
\hline 663W-u50 & 26.43 & & $663 N-s 50$ & 15.56 & & 663S-s50 & 19.88 & \\
\hline $663 W-u 25$ & 23.08 & & $663 N-s 25$ & 15.41 & & 663S-s25 & 17.46 & \\
\hline 663E-s100 & 20.47 & \multirow{4}{*}{$8 \uparrow$} & 663W-s100 & 21.00 & \multirow{4}{*}{$8 \uparrow$} & & & \\
\hline 663E-s75 & 20.88 & & $663 W-s 75$ & 19.73 & & & & \\
\hline 663E-s50 & 19.78 & & $663 \mathrm{~W}$-s50 & 18.96 & & & & \\
\hline 663E-s25 & 18.91 & & $663 W-s 25$ & 19.40 & & & & \\
\hline
\end{tabular}




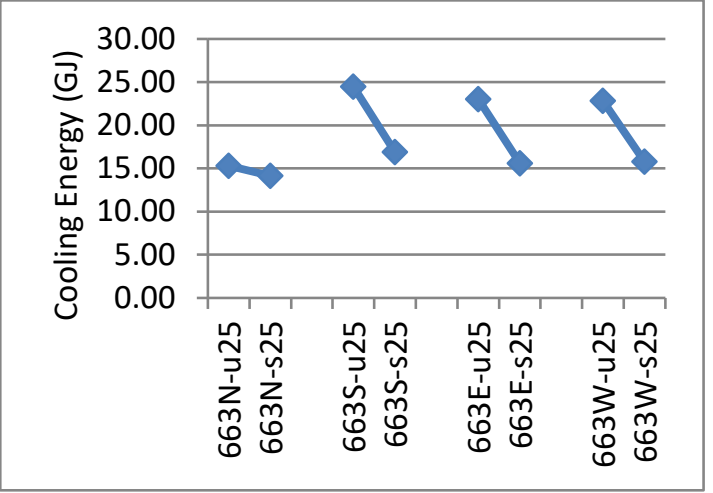

Fig 14: Effect of shading and orientation on cooling energy when window to Wall ratio is $25 \%$.

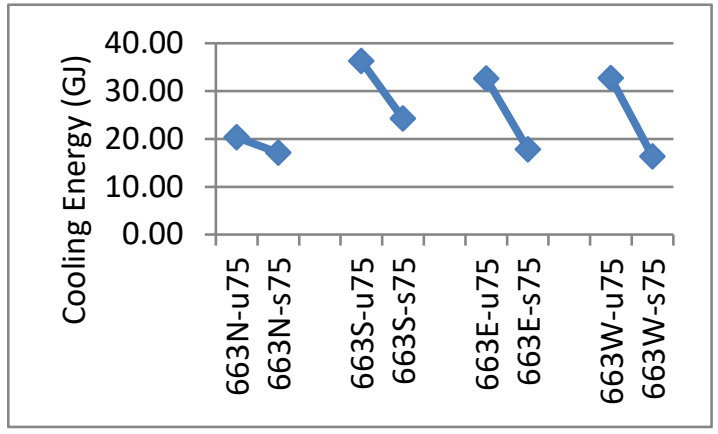

Fig 16: Effect of shading and orientation on cooling energy when window to Wall ratio is $75 \%$.

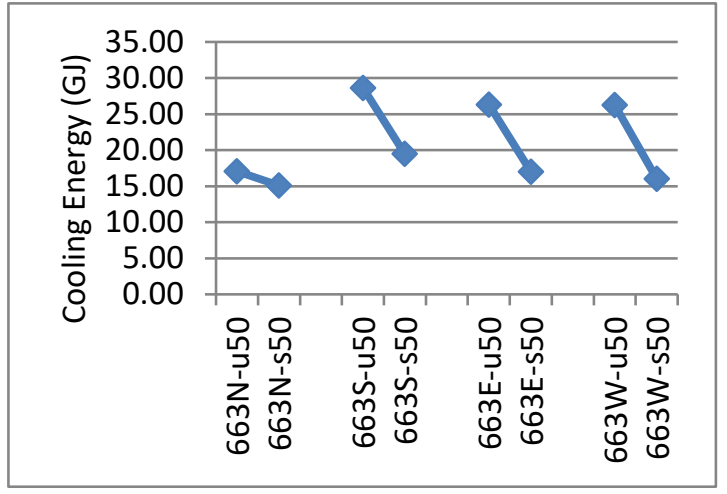

Fig 15: Effect of shading and orientation on cooling energy when window to Wall ratio is $50 \%$.

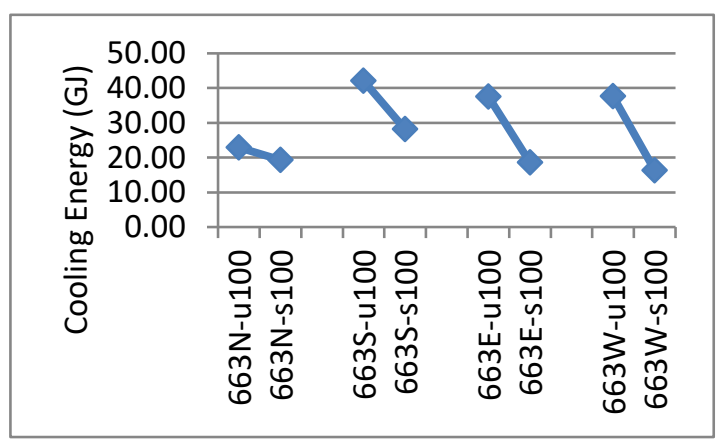

Fig 17: Effect of shading and orientation on cooling energy when window to Wall ratio is $100 \%$.

For all "window to wall" ratios (Fig. 14, 15, 16, 17), the north window is far less crucial than other three sides, because introduction of shading reduces only $8 \%$ to $16 \%$ cooling energy depending on the size of the window.

But the other 3 sides specially the East and West windows (that are bigger, say more than 50\% of the wall) around 50\% cooling energy is reduced when shading is provided. In case of smaller windows (less than 50\% of the wall) the reduction is rather moderate around $31 \%$ to $35 \%$ in all the 3 directions- south, west and east.

Among all the orientations, cooling load increases with bigger windows whether shaded or not; the south is the most crucial because the south window is responsible for largest cooling load, followed by east and west. The north window is significantly less responsible. If not shaded, it generates $37 \%$ to $46 \%$ less cooling load than south window and if shaded, $16 \%$ to $30 \%$ less. But shading increases performance of other windows. Bigger east and west shaded windows (75\% 100\%) improve performance by reducing cooling load by $45 \%$ to $57 \%$.

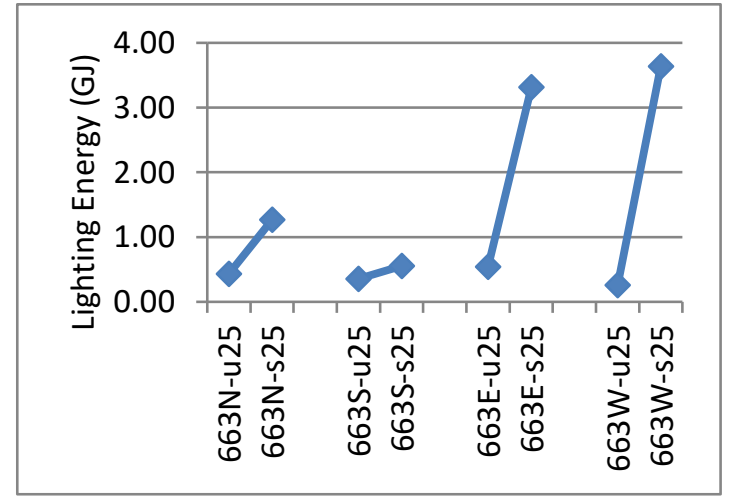

Fig 18: Effect of shading and orientation on lighting energy when window to Wall ratio is $25 \%$.

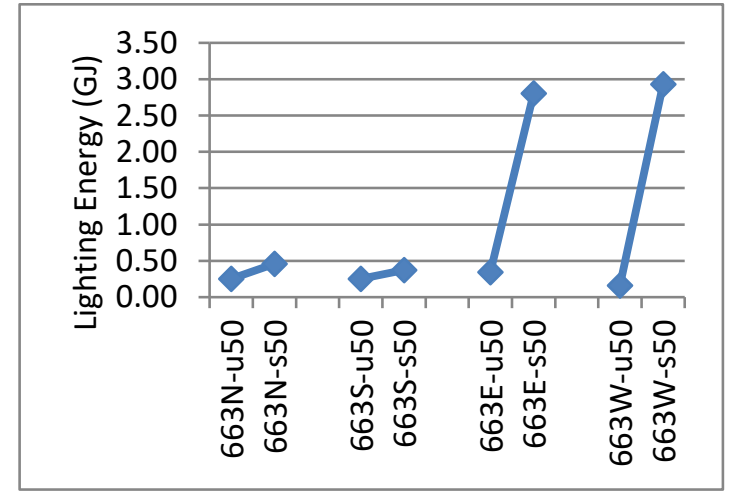

Fig 19: Effect of shading and orientation on lighting energy when window to Wall ratio is 50\%. 


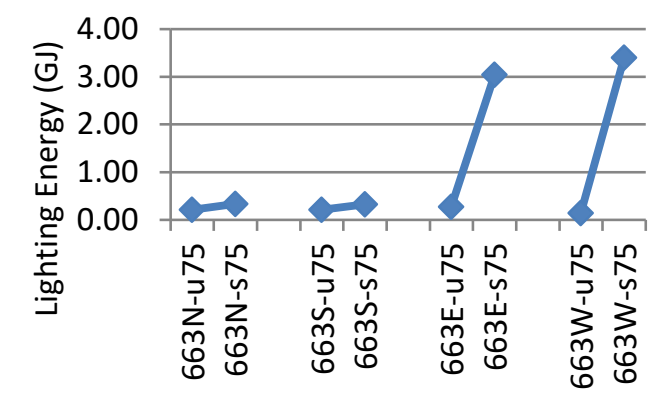

Fig 20: Effect of shading and orientation on lighting energy when window to Wall ratio is $75 \%$.



Fig 21: Effect of shading and orientation on lighting energy when window to Wall ratio is $100 \%$.

For almost all sizes of un-shaded windows (Fig. 18, 19, 20, 21) the lighting energy requirement is pretty same or nearby. Regardless of the size of window, it travels in the close range of $0.13 \mathrm{GJ}$ to $0.54 \mathrm{GJ}$ for all the year round compared to that of shaded windows.

Shading increases lighting energy requirements for all size of windows; but for East and West orientation the increment is quite high compared to North and South.

The south window shows the least increment of lighting energy, consistent at around 33\%-35\% range. The north window performs similar but a bit higher, in 38\% $-66 \%$ range, but the bigger the better.

The east and west windows, when shaded, shows a big jump in lighting energy requirements, having a range of $84 \%-$ $96 \%$ regardless of the size of window.

From Fig 22, it is clear that cooling energy is significantly higher than lighting energy which increases with the window size; especially for the windows bigger than $50 \%$, the ratio is very high and hence the two are not comparable. Only for models with east and west shaded windows, the ratio is small and the two are comparable, although the cooling energy is always higher than lighting energy. The fig 24 and 25 shows that the cooling energy increases a little or remains same until the window size is $75 \%$; but after that it increases sharply.

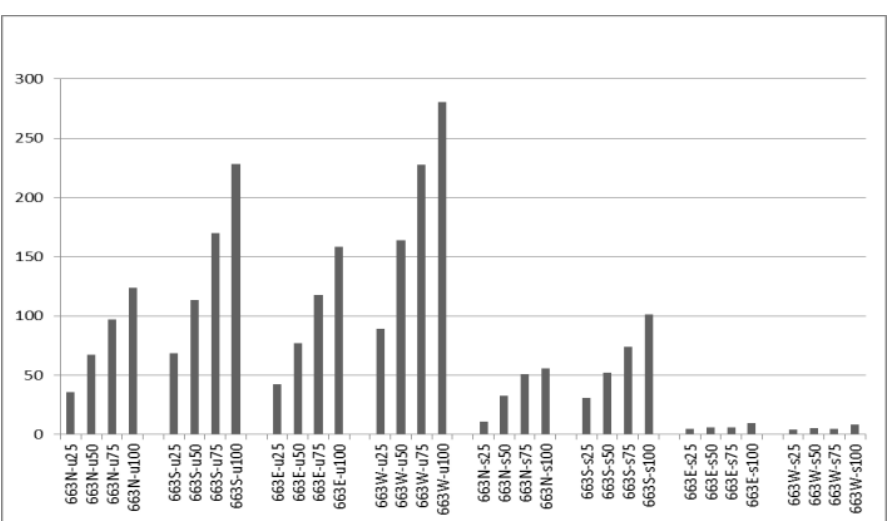

Fig 22: Cooling to lighting energy ratio in different models.

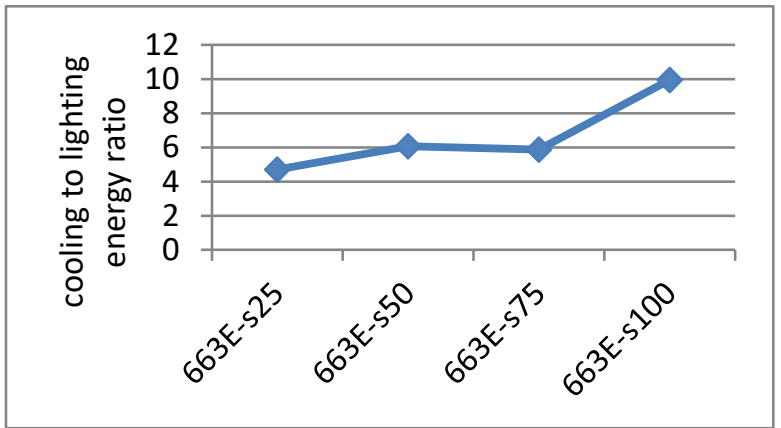

Fig 24: Effect of Glazing to Wall ratio on cooling to lighting energy ratio on the East.

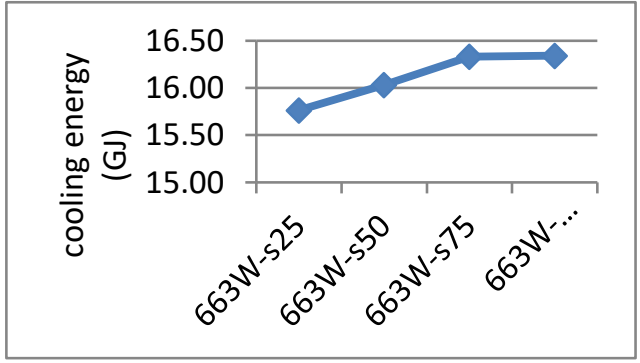

Fig 23: Effect of Glazing to Wall ratio on cooling energy on the West.

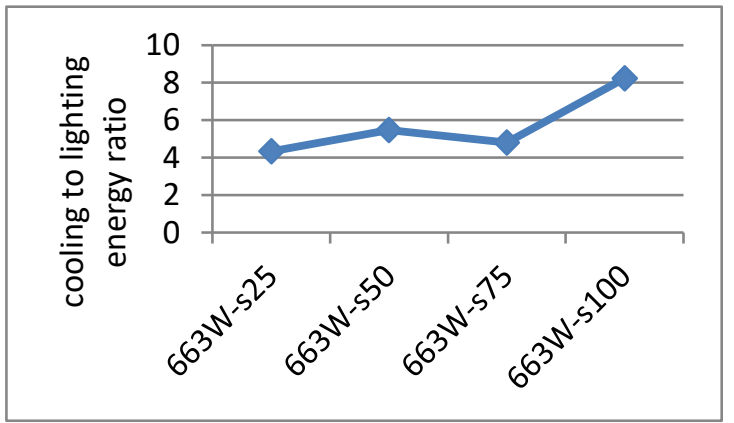

Fig 25: Effect of Glazing to Wall ratio on cooling to lighting energy ratio on the West. 
Among all others, cooling energy for west window increases with window size but after $75 \%$ window, it remains same (Fig 23).

The table 3 shows the total energy increment with window size. For south, energy requirement increases up to $70 \%$ along with window size, shaded or not. But the scenario is dramatically different for east and west. Without shading the energy requirement increases up to $60 \%$ with window size, but if shaded its maximum $8 \%$. Therefore there is big opportunity to use large windows on east and west but with proper shading. The north window shows a moderate result.

It is clear that shaded south windows of all sizes shows a preferable combination.

Therefore, the results might be interpreted as:

- With shading provided, the south window reduces cooling energy requirement and the same time the increment of lighting energy is very moderate compared to other combinations.

- Providing shade, the bigger windows (especially more than 50\%) on the east and west shows a crucial relationship between decrease of cooling and increase of lighting energy;

- For the present study the cooling is still higher numerically but when other parameters (like different glazing construction, wall with thermal mass, brighter interior etc.) would be included, the study might show different results, and it applies to both the observation above.

- To consider only cooling, for all window sizes- shading reduces $1 / 3$ cooling load on the south; but much improved performance on east and west- $50 \%$ reduction if the window is bigger than $50 \%$.

- To consider total energy, the requirement is reduced to $1 / 3$ for south, to $1 / 2$ for the east and west when window size is $50 \%$ or bigger.

\section{CONCLUSION}

Energy consumption "by lighting" is substantially less than "by cooling" and hence not comparable in most cases. But the results for shaded east and west windows were interesting. The study reestablishes the century old knowledge about necessity of proper shading in the windows in this context; but at present in Dhaka various new technologies such as rotatable louvers of bright colors, double or triple glazing with low-E coating etc. and architectural styles such as full glazed façade, use of vegetation on or in front of the façade etc. are being introduced in high rise buildings. Those might bring change to the luminous and thermal behaviors of high rise office buildings. As found in the study, the luminous and thermal behavior of office space with bigger windows (as $100 \%$ or $75 \%$ ) that represent full glazed façade, is crucial; using modern louvers might improve the performance, by cutting the sun as a first line of defense, air space in between the plane of louvers and building might help convective cooling of the heat accumulated in louvers; and at the same time daylight reflected from louvers improve the luminous performance and hence reduce energy requirement for both lighting and cooling. The north sided windows don't show much difference in energy requirement while shading is provided, therefore bigger windows to provide natural light and view for healthy environment might get consideration of the designer rather than just shading or smaller window.

Although the south windows show a consistent behavior regardless of size and are responsible for the maximum cooling load, deserves highest attention. Also as the solar altitude angle is high, the south façade offers excellent opportunity to play with, to reduce cooling load and lighting energy by proper and innovative shading.

At present almost all the developments in Dhaka for high rise office buildings are redevelopments of old buildings in tight urban sites due to extreme shortage of land. Therefore having predefined and dense surrounding atmosphere is an obvious possibility. Depending on the site, surrounding and orientation, it is important to design or modify the façades for maximum daylight and at the same time least cooling load.

\section{REFERENCES}

Al-Homoud, M. (1997). "Optimum thermal design of office buildings". International Journal of Energy Research, 21, pp. 941-957.

BODART, M. And De Herde, A. (2002). “Global energy savings in offices buildings by the use of daylighting”. Energy And Buildings, 34(5), pp.421-429.

CHOUDHURY, J. R. (1990). Tall Building Developments in Bangladesh. In:Fourth World Congress on Tall Buildings: 2000 and Beyond, Hong Kong: Council for Tall Buildings and Urban Habitat.

DANNY H. W. (2001). "Evaluation of lighting performance in office buildings with day lighting controls". Energy And Buildings, 33, pp.793-803. 
FRANZETTI, Christelle et al. (2004). "Influence of the coupling between daylight and artificial lighting on thermal loads in office buildings". Energy And Buildings, 36, pp.117-126.

GIVONI, Baruch. (1992). "Comfort, climate analysis and building design guidelines". Energy and Buildings, 18, pp.1123.

GORDON, Jeffrey. (2001). Solar energy: the state of the art: ISES position papers. UK: James \& James ltd.

GRATIA, E. and De Herde, A. (2003). “Design of low energy offices”. Energy and Buildings, 35, pp.473-491.

HEGGER, Manfred et al. (2008). Energy Manual: Sustainable Architecture. Munich: Birkhäuser.

JOARDER, M.A.R. et al, (2009). Daylight simulation for sustainable urban office building design in Dhaka, Bangladesh: decision-making for internal blind configurations. In: Second International Conference on Whole Life Urban Sustainability and its Assessment. Loughborough: SUE-MoT.

KOENIGSBERGER, Otto H., et al. (1980). Manual of tropical housing and building: Climatic design. London: Longman.

LEHAR, M.A. (2007). "Rapid algorithm for modeling daylight distributions in office buildings". Building and Environment, 42, pp.2908-2919.

LOMBARD, Luis Perez, et al. (2008). "A review on building energy consumption information". Energy and Buildings, 40(3), pp. 394-398

MAHTAB-UZ-ZAMAN, Q.M. and Lau, Stephen S.Y. (2000). City Expansion Policy versus Compact City Demand: The Case of Dhaka. In: JENKS, Mike and BURGESS, Rod, ed., Compact Cities, 1st ed. NY: Spon Press.

MALLICK, Fuad H. (1996). "Thermal Comfort and Building Design in Tropical Climate". Energy and Buildings, 23, pp.161-167.

MOURSHED, M..(2011). "The impact of the projected changes in temperature on heating and cooling requirements in buildings in Dhaka, Bangladesh". Applied Energy, 88 (11), pp. 3737 - 3746.

MRIDHA, A.M.M.H. (2002). A study of Thermal Performance of Operable Roof Insulation with Special Reference to Dhaka. M. Arch. Department of Architecture, BUET, Dhaka.

PARVEEN, Rehnuma. (2004). Wind on Highrise Apartments with respect to Height \& Orientation. M.Arch. Department of Architecture, BUET, Dhaka.

PARYS, Wout, et al. (2009). Optimization of energy use for heating/cooling and lighting for a typical office room in a moderate climate. In: The 6th International Symposium on Heating, Ventilating and Air Conditioning. Nanjing: Southeast University

POIRAZIS, Harris. (2008). "Energy simulations for glazed office buildings in Sweden". Energy and buildings, 40(7), pp.1161 - 1170 .

RAHMAN, Anisur. (2007). Performance Evaluation of Shading Devices in Tall Office Buildings of Dhaka, M.Arch. Department of Architecture, BUET, Dhaka.

RAHMAN, Anisur. (2008). “Observations on Performance of Commonly Used Shading Devices in Tall Office Buildings of Dhaka". Protibesh, 12(2), pp. 15-26.

TRISHA, S.H. and Ahmed, Zebun, 2016, Light Zones vs. HVAC Loads: evaluating energy efficiency for shading devices in commercial buildings. In: 32nd International Plea Conference. Los Angeles: PLEA2016

\section{Websites and Other Sources}

ASHRAE (American Society of Heating, Refrigerating, and Air Conditioning Engineers) [online] available at: http://www.ccohs.ca/oshanswers/phys_agents/thermal_comfort.html [accessed 13 August 2014]

BNBC (Bangladesh National Building Code). (2006). Extra Gazette.

BPDB (Bangladesh Power Development Board) [online] available at: http://www.bpdb.gov.bd/bpdb [accessed 25 August, 2012]

BSS (Bangladeh Shangbad Shnagatha, national news agency) [online] available at: www.bssnews.net [accessed 25 August, 2012]

CSA (Canadian Standards association) and CCOHS (Canadian Center for Occupational Health and safety) [online] available at: http://www.ccohs.ca/oshanswers/phys_agents/thermal_comfort.html [accessed 2 September 2012]

Emporis: Global provider of building information [online] available at: http://www.emporis.com/corporate [accessed 25 August, 2012] 
Hossain: A Parametric Study Qf Window, Drientation And Shading to Minimize Energy Consuption in Mechanically Ventilated High Rise Qffice Buildings in Dhaka, Bangladesh (27-38)

Energy Plus: Energy simulation software from US Department of Energy. [online] available at: http:/ /apps1.eere.energy.gov [accessed 2 August, 2012]

The Daily NEWSTODAY [online] available at: http://www.newstoday.com.bd [accessed 25 August, 2012)

-- 0 -- 